\title{
What do Computer Scientists Know About Conflict Minerals?
}

\author{
Inès Moreno Boluda \\ McGill University \\ Montréal, Québec, Canada \\ ines.moreno@mail.mcgill.ca
}

\author{
Elizabeth Patitsas \\ McGill University \\ Montréal, Québec, Canada \\ elizabeth.patitsas@mcgill.ca
}

\author{
Peter McMahan \\ McGill University \\ Montréal, Québec, Canada \\ peter.mcmahan@mcgill.ca
}

\begin{abstract}
Despite low public awareness, significant social and environmental impacts are associated with computer hardware manufacturing. Particularly, many consumers do not know about conflict minerals, which are used in electronics' components and whose extraction is associated with widespread human rights abuses and environmental destruction. The literature about these minerals focuses on explaining the conflict as well as commenting and describing the legislation and other solutions that have emerged over the years to tackle this issue. This study aims to investigate the public awareness around these topics amongst computing professionals. Through an online survey, the level of familiarity of such professionals with conflict minerals was analyzed, as well as their knowledge about other socio-environmental impacts of the electronics industry. This study unveils the ignorance in the computer science community about this issue and proposes ways in which this gap of knowledge could be filled.
\end{abstract}

\section{CCS CONCEPTS}

- Social and professional topics $\rightarrow$ Computing education; Sustainability; Computing profession.

\section{KEYWORDS}

conflict minerals, social and environmental impacts of electronics, computer hardware

\section{Reference Format:}

Inès Moreno Boluda, Elizabeth Patitsas, and Peter McMahan. 2021. What do Computer Scientists Know About Conflict Minerals?. In LIMITS '21: Workshop on Computing within Limits, fune 14-15, 2021.

\section{INTRODUCTION}

Hardware manufacturing raises a number of ethical, social and environmental justice issues [44]. Examples of such issues include, but are not limited to: the mining of rare-earth minerals for the components of consumer electronics [31, 42], the poor health and safety conditions of workers in hardware manufacturers [26, 37], the international trade of toxic e-waste [36], or the increasing energy costs required to produce and power such devices.

Historically, the exploitation of natural resources has played an important role in conflict; especially in nation-states formed during the second half of the 20th century whose early-development was

Permission to make digital or hard copies of part or all of this work for personal or classroom use is granted without fee provided that copies are not made or distributed for profit or commercial advantage and that copies bear this notice and the full citation on the first page. Copyrights for third-party components of this work must be honored. For all other uses, contact the owner/author(s).

LIMITS '21, fune 14-15, 2021,

(c) 2021 Copyright held by the owner/author(s). heavily impacted by two global wars and a polarized world [1]. More specifically, conflict minerals (3TG) are minerals processed into tin (cassiterite), tungsten (wolframite), tantalum (coltan) and gold that originate from the Democratic Republic of Congo (DRC) and whose extraction is associated with the funding of ongoing conflict in the Kivu region, an eastern region of the country. These minerals are particularly used in consumer electronics such as computers, tablets or smartphones for a variety of reasons. For instance, tin is used as a solder on circuit boards, tungsten is what makes smartphones vibrate, tantalum is used in capacitors and gold is used to coat wirings. Estimates say that in 2013 the use of such minerals in information and communications technology (ICT) products contributed to $2 \%, 0.1 \%, 15 \%$ and $3 \%$ of the mining of tin, tungsten, tantalum and gold, respectively [13].

\subsection{Motivation}

Research concerning conflict minerals and their use in electronics has mainly focused on reporting concerns about the topic, as well as commenting on and studying the effects of different international efforts to reduce the trade of such minerals [21, 41, 52]. However, little to no research has been done on investigating popular knowledge and awareness of the topic.

The ICT industry is growing worldwide. In 2019 the Canadian ICT sector employed 666,544 people and contributed to $3.6 \%$ of the country's economy [16]. Since computer scientists use these technologies in their day-to-day professional practice, an important question arises: what do computer scientists know about conflict minerals?

This study aims to investigate the degree of awareness of computing professionals about the social and environmental impacts of technology, especially about the use of conflict minerals in the components of everyday electronics. To do so, an online survey was conducted in which computer scientists were asked to assess their level of familiarity with each conflict mineral and report on what they know about them, as well as the possible solutions and actions that could be taken to solve these issues.

This paper starts by giving an overview of what conflict minerals are and how this research fits into the existing literature, followed by a presentation of research methods and findings. Finally, this paper concludes by discussing the results, examining the possible limitations, and proposing several directions for future inquiry.

Pargman et al., wrote about the links between computing and non-renewable materials (e.g. copper) and how the current path of innovating fails to account for resource scarcity and global justice [35]. With this study, we contribute to the LIMITS community by shedding some light on the current status quo of computing professionals' relationship with the impacts of their practice, and giving some direction to challenge it and shift towards a future where computing is done within limits [33]. 


\section{BACKGROUND}

The term 'conflict minerals' refers to tin, tantalum, tungsten and gold (3TG), minerals which are extracted in conflict zones in the DRC and whose selling perpetuates and funds these conflicts. These minerals are mainly mined in the Eastern regions of the DRC (Kivu Region), where in 2017, researchers identified more than 120 different armed militias who control the mines and tax their products [50]. Rebel and militia groups commit widespread human rights abuses including rape, enslavement, torture, kidnapping and killing of civilians. They also employ high rates of child labor [38].

The conflict in Congo is widespread and has been ongoing for over 20 years. It is known to be one of the deadliest conflicts in the world since World War II, as over 5.4 million people have died since 1998 [10]. Officially, the Second Congo War lasted until 2003, but its aftermath is still impacting mineral rich regions of the country. Armed groups not only control mines, but minerals mined in the DRC are then illegally smuggled across the border to neighboring countries such as Uganda or Rwanda to then arrive to Asia where they are smelted and transformed into components that we find in a variety of consumer goods, especially electronics [39].

Unfortunately, there are not only social impacts related to the mining of these minerals but also many environmental and health issues. Most of the mining done is artisanal which means minerals are predominantly extracted and processed manually, with minimal or no mechanization. Artisanal and Small Scale Mining (ASM) has been proven to be highly toxic for the miners; studies have shown that metal contamination can cause many health problems, including birth defects [49]. Furthermore, mines are usually located in remote zones near wildlife reserves, and the mining operations attract populations who settle there and disrupt the habitat of species, contributing to landscape alterations, loss of biodiversity and water pollution $[6,45]$. $^{1}$

Over the years, there have been many international efforts to reduce the trade of conflict minerals. The first major effort was in 2010, when the United States adopted the Dodd-Frank Act which required manufacturers to audit their supply chains and report if they used conflict minerals [52]. However, companies usually have very complicated supply chains and a study conducted in 2016 showed that more than $80 \%$ of the companies could not determine the country of origin of their minerals and only $1 \%$ could certify themselves as being $100 \%$ conflict-free [24]. In 2011, the Organisation for Economic Co-operation (OECD) published due diligence guidelines to be followed by companies to ensure that the minerals they use in their products are not sourced in conflict zones. These guidelines were later ratified into national law by the Congolese Government in 2012 [40].

Many international organizations, non-governmental organizations and celebrities are working to find solutions and raise awareness on this topic. For example the FairPhone foundation, which started as a campaign, released in 2013 its first 'fair' smartphone [22]. Nevertheless, even Fairphone's founder acknowledged in 2017

\footnotetext{
${ }^{1} \mathrm{ASM}$ is only legal in the DRC when operated within the officially designated artisanal mining zones and when the miner respects the conditions specified in 2002 Mining Code and the 2003 Mining Regulation's ASM Code of Conduct. With only one legal artisanal mining zone in the whole country, practically all ASM is practiced illegally [19].
}

that it was currently impossible to produce a $100 \%$ fair phone, suggesting it was more accurate to call his company's phones "fairer" [46].

Whilst Fairphone showcases that more ethical electronics can be produced, only a "tiny minority of consumers well-connected to informational flows surrounding the ethics and ecologies of the the global microelectronics industry" [45] opt for this kind of technology. This is part of a larger sociological trend that McKay terms dis-origining, referring to how objects have their material origins obscured to the user [32]. Dis-origining allows the violent and destructive origins of materials to stay out of sight and out of mind, obviating the need to change extractive processes. (For a review of how obscuring material origins contributes to the climate crisis see [32].) There is hence a need to increase the awareness around social and environmental impacts of technology because social awareness is the first step towards change.

\section{METHOD}

For the purposes of this study, both quantitative and qualitative data were needed in order to assess the level of awareness of computer scientists about the social and environmental impacts of electronics (especially conflict minerals). Initially, interviewing members of the CS community in both academia and industry was considered, however, due to the time constraints of this study, a survey approach was finally chosen.

\subsection{Questionnaire}

An online survey was deployed and distributed to individuals in the Computer Science community in both academia and industry. Participants were asked to answer a total of 12 questions which were divided into 3 different sections (cf. Appendix A).

The first set of questions aimed to collect demographic information about the participants: age group, highest level of education, most recent occupation and specialty within the Computer Science discipline. The ACM Computing Classification System was used as reference for participants to select their specialty within computing. The options participants could select were: hardware, computer systems organization, networks and web/mobile computing, software and its engineering, theory of computation, mathematics of computing, information systems, security and privacy, human-centred computing, computing methodologies (artificial intelligence, machine learning, graphics, etc), applied computing, and social and professional issues in computing. An 'other' option was provided in case participants wanted to add another specialty that was not included in the list.

The second set of questions investigated the familiarity of participants with conflict minerals. They were first asked to provide a list of things that came to mind when hearing the term as well as the places from where they have learned about conflict minerals.

Then, they were asked to rate their familiarity with how each of the four conflict minerals is used in electronics, the environmental effects of each mineral and their social effects. For each of these 12 questions, participants rated their knowledge on a Likert scale. For the use of conflict minerals in electronics, options on the scale ranged from "Didn't know it's used" to "Expert on this" passing through "Know it's used", "Know a bit about use" and 
"Familiar"; and for the environmental and social impacts of each conflict mineral options on the scale were "Unfamiliar", "Vaguely familiar", "Somewhat familiar", "Familiar" and "Expert on this".

Finally, a series of open-ended questions were included in which participants could list other social and environmental impacts of electronics they were aware of, solutions for these impacts and whether or not they had taken action or contributed to causes related to solve any of these issues.

The survey was initially hosted in Google Forms and participation was completely voluntary and anonymous. Participants could at any time decline to answer a question or withdraw from the study, in which case all their information would be destroyed. Because Google Forms data is presumed to be stored in the United States and would be subject to US state surveillance (i.e. Patriot Act), a second version of the survey was created on McGill's domestically-hosted Microsoft Office survey platform. Both surveys were identical and made available to participants for them to choose which one they preferred to fill in.

\subsection{Recruitment}

To capture a variety of participants in both academia and industry, recruitment was performed via email and social media (Twitter and Linkedin)(cf. Appendix B). The survey was sent to a variety of mailing lists including McGill's CS professors mailing list, Mila's (Quebec Institute of Learning Algorithms) mailing list and several ACM SIGs mailing lists (SIGCSE, SIGAI, SIGARCH, SIGCAS, SIGMETRICS, SIGSAN, SIGCHI, SIGCOMM and SIGMOBILE).

\subsection{Pseudo-Qualitative Analysis}

In order to gain a better insight into what participants knew about conflict minerals, which other social and environmental impacts of electronics they were aware of, which solutions they could think of and which actions they had taken to contribute to any of these causes; participants' responses to the survey's open-ended questions were analyzed. A thematic analysis was conducted which involved coding all the data and then identifying and labeling common themes mentioned in each response.

To do so, participants' responses were recorded on a spreadsheet's column and sequentially read through, identifying the core topics mentioned. For each new topic, a column was added onto the spreadsheet, and for each new mention of a topic in a response, an ' $x$ ' was marked in the cell whose row corresponded to the participant's response and whose column corresponded to the mentioned topic, as demonstrated in Table 1.

\begin{tabular}{|l||c|c|c|c|}
\hline Responses Topics & Topic 1 & Topic 2 & Topic 3 & $\ldots$ \\
\hline \hline Response A & $\mathrm{x}$ & & & \\
\hline Response B & & $\mathrm{x}$ & & \\
\hline Response C & & $\mathrm{x}$ & $\mathrm{x}$ & \\
\hline$\ldots$ & & & & \\
\hline
\end{tabular}

Table 1: Pseudo-Qualitative data analysis example

Following this preliminary step, the mentions of each topic were counted and topics were reorganized and grouped together if they belonged to the same theme (e.g. mentions of rare minerals, metals, chemicals or diamonds were grouped together under the label "raw materials").

\subsection{Quantitative Analysis}

In order to investigate correlations between participant demographic information and their level of familiarity with conflict minerals, a bayesian statistical analysis was performed using R. ${ }^{2}$ The gathered data from the survey was prepared beforehand.

First, twelve ordinal independent variables were prepared corresponding to the level of familiarity with the use, environmental impacts and social impacts of each conflict mineral (GOLD.USE, GOLD.ENV, GOLD.SOCI, TIN.USE, TIN.ENV, TIN.SOCI, etc.). Values for these variables ranged from 0 to 4 ; 0 corresponding to totally unfamiliar and 4 for expert knowledge.

Then, twenty-four dependent variables were prepared:

- Two ordinal variables representing the age groups (age), and the levels of education (educ). From lowest to highest, a number was attributed to each age group (0-5) and to each level of education $(0-4){ }^{3}$

- One categorical variable representing categories of occupation (occ). The value for this variable was 0 if the participant was in academia, 1 if they were in industry and 2 if they were in neither of them.

- Twelve binary nominal variables representing each specialty (hardware, software, etc.) The value for the nominal variables was either 0 or 1 depending on whether or not that particular participant had that specialty or had learned about conflict minerals from that particular source.

- Ten binary nominal variables representing the places from where participants had learned about conflict minerals (friends, documentaries, etc.) The ten sources of knowledge about conflict minerals were defined by doing a pseudo-qualitative analysis of the open-ended question "Where have you learned about conflict minerals from?", as described in subsection 3.3.

Once all the data was prepared, a nonlinear principal component analysis (NLPCA) was performed using the package homals in order to reduce the dimensionality of the data set. Three different clusters were found and each cluster was individually modelled using Bayesian inference to estimate the relationships between each dependent variable and that particular cluster. To obtain better predictions, we assumed the effects of our ordinal variables (age and education) to be monotonic [7].

\section{RESULTS}

\subsection{Demographics}

We received survey responses from 135 participants; 73 from academia, 47 from industry and 15 from other. Of the 135 survey participants, most respondents were in the 46-55 age bracket (cf. Figure 1 for more details).

In terms of education, the majority of participants were highly educated; most of them had a Doctorate and the rest had either a

\footnotetext{
${ }^{2}$ The code is available here: https://github.com/inesmoreno/Survey-data-Analysis/

${ }^{3}$ None of the participants marked CEGEP or community college as their level of education and, high school and certification program were merged into one same level because there were only one participant in each.
} 


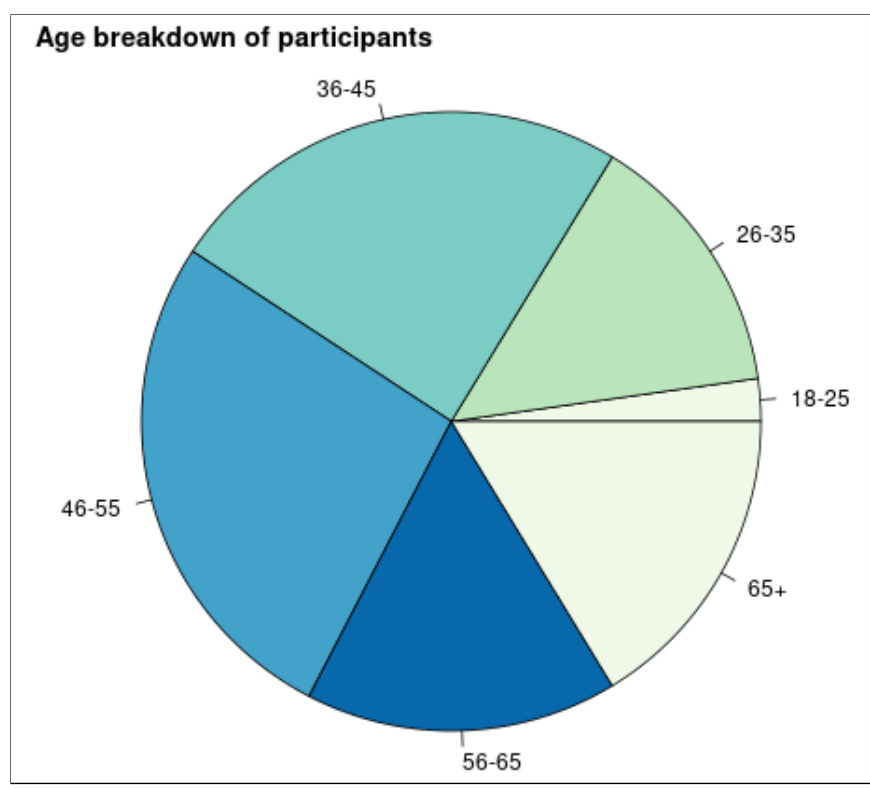

Figure 1: Age group distribution. 46-55 was the most common group; similar numbers between 26-35, 26-45, 56-65 and 65+. The 18-25 age group is much slimmer than the others.

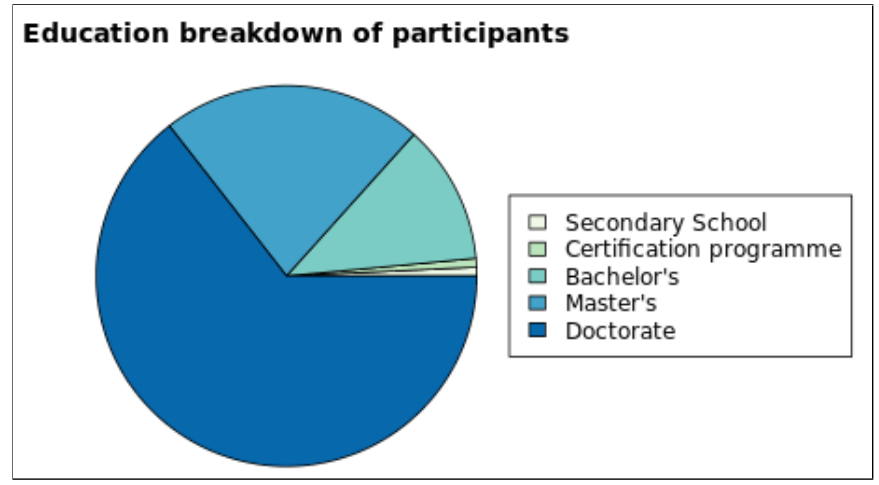

Figure 2: Highest level of education distribution. About two thirds have a doctorate; about $1 / 6$ have a master's, about 1/8 have a bachelor's, and the remaining sliver is people who have secondary school or a certification programme.

Master's degree or a Bachelor's degree. Only 1 respondent had only finished secondary school, and one other had done a certification program (cf. Figure 2 for more details).

Among respondents, the most common specialties were computing methodologies (51\%) and software and its engineering (41\%) This is likely due to the choice of mailing lists when recruiting participants, for instance all of the respondents who came through Mila's or SIGAI's mailing list were presumably AI and/or ML experts (cf. Figure 3 for more details).

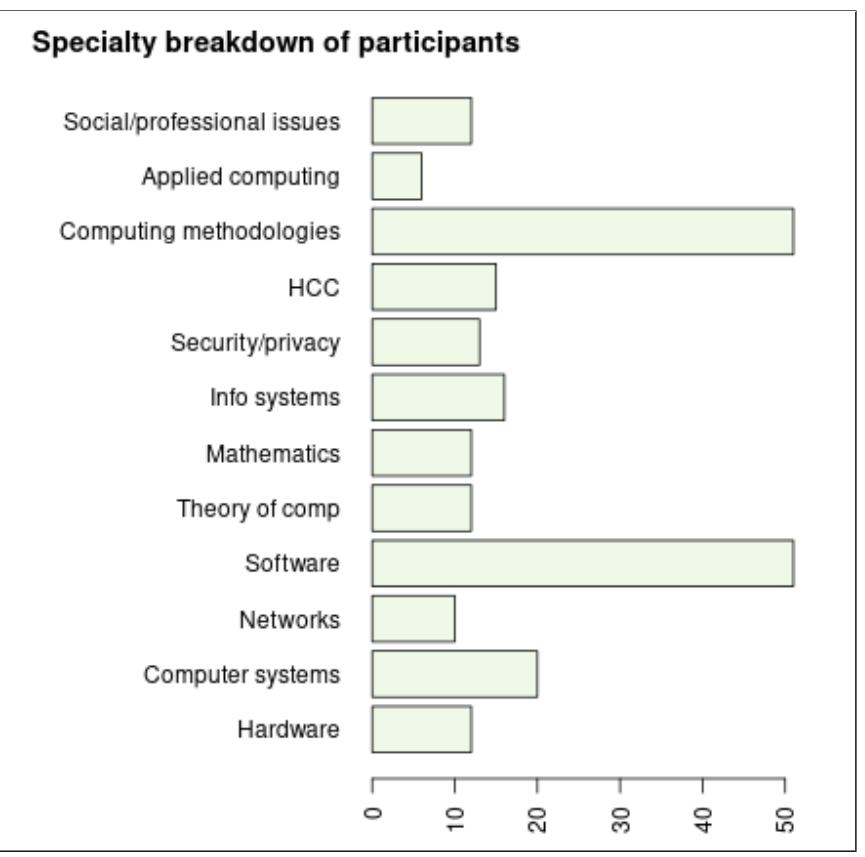

Figure 3: Specialties distribution. Two bars are much larger than the others: software, and computing methodologies (which includes AI/ML).

\subsection{Familiarity with conflict minerals}

In terms of knowledge about conflict minerals, a vast majority of the participants did not know about them or knew very little. However, participants seemed to know more about the use of the minerals in electronics rather than about their socio-environmental impacts. Furthermore, participants seemed to know more about gold than about the other three conflict minerals (cf. Figures 4, 5 and 6 for more details).

After establishing descriptive statistics, our next goal was to model participant knowledge of conflict minerals. However, we had 12 possible independent variables (Gold/Tin/Tungsten/Tantalum) $\mathrm{x}$ (Use/Social effects/Environmental effects). So, we performed a principal component analysis using homals to see if there were clusters amongst the 12 variables. We observed 3 different clusters (Figure 7):

(1) The first cluster represents participants that knew about societal impacts of gold;

(2) The second cluster represents participants that knew about the use of gold, the environmental impacts of gold, and the use of tin;

(3) The last cluster represents participants that knew about the remaining factors.

Each of the three clusters were then modelled using a Bayesian inference model with the package brms to identify the factors by which they were influenced.

The results are presented in Figures 8, 9 and 10. To determine which variables play an important role in determining each cluster, we examined which ones' $95 \%$ credible interval did not cross 0 . 


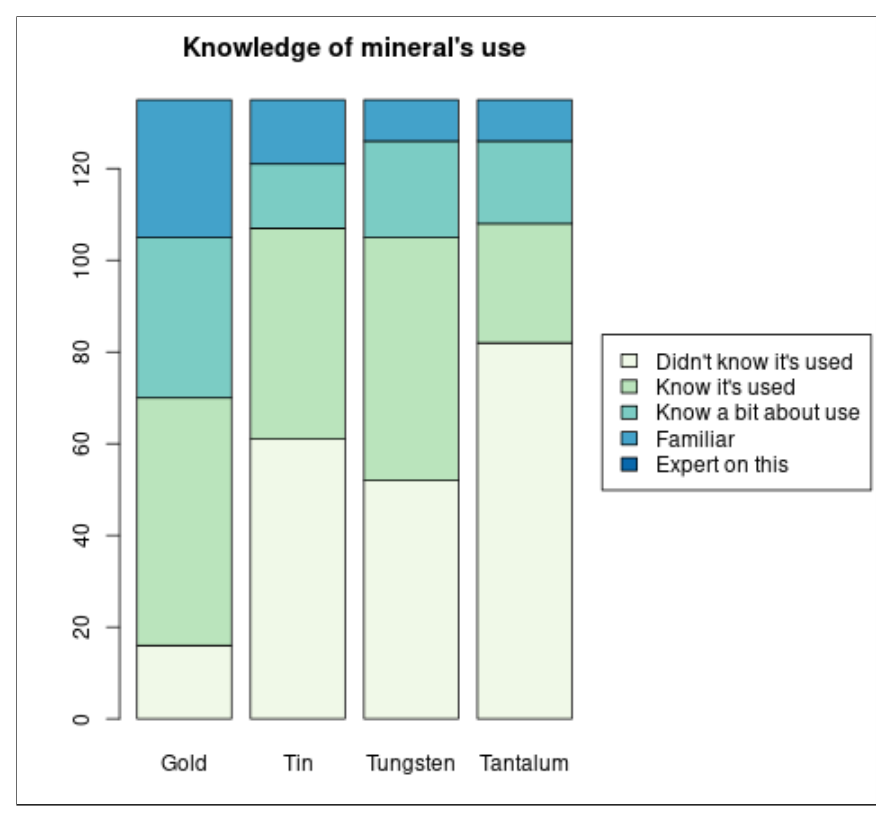

Figure 4: Distribution of participant's knowledge about the use of conflict minerals in electronics. For tin, tungsten, and tantalum, the most common response is "Didn't know it's used". For Gold it is "Know it's used". Fewer people selected "Didn't know it's used" for this question than "Unfamiliar" with the environmental impacts.

Knowledge of mineral's environmental impacts

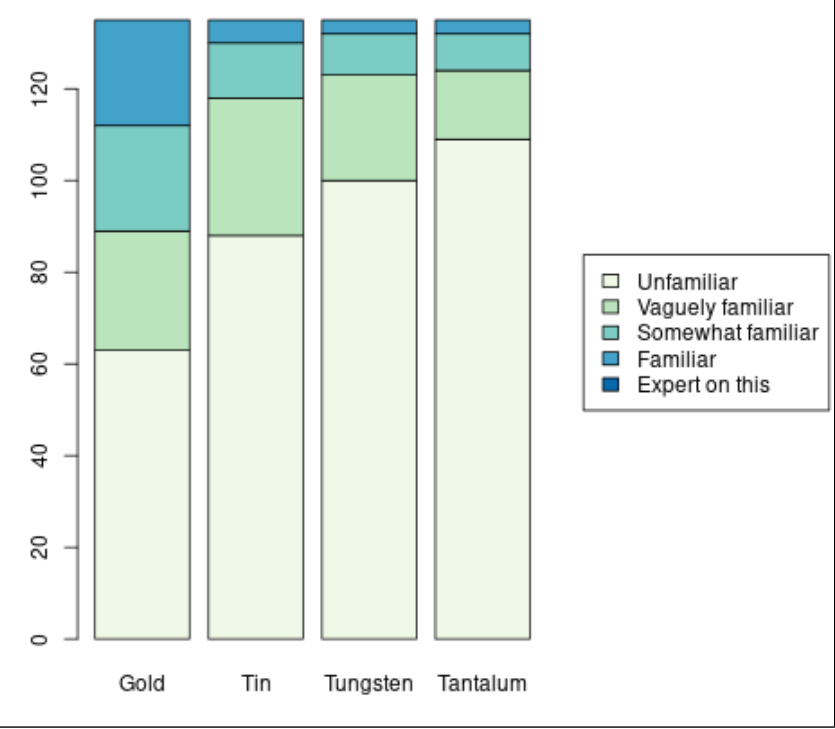

Figure 5: Distribution of participant's knowledge about the environmental impacts of conflict minerals. For all four minerals the most common response is "Unfamiliar". Gold has the most who are not unfamiliar; tantalum has the least.

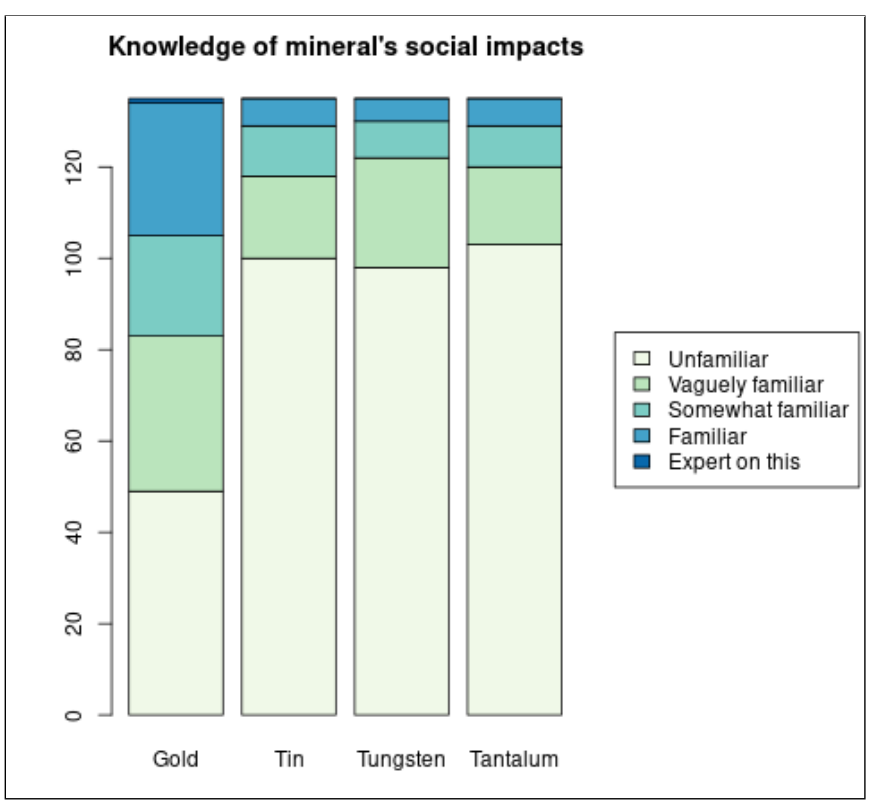

Figure 6: Distribution of participant's knowledge about social impacts of conflict minerals. The figure looks very similar to Figure 5. The most common response is "Unfamiliar" but less frequent for gold than for the three Ts.

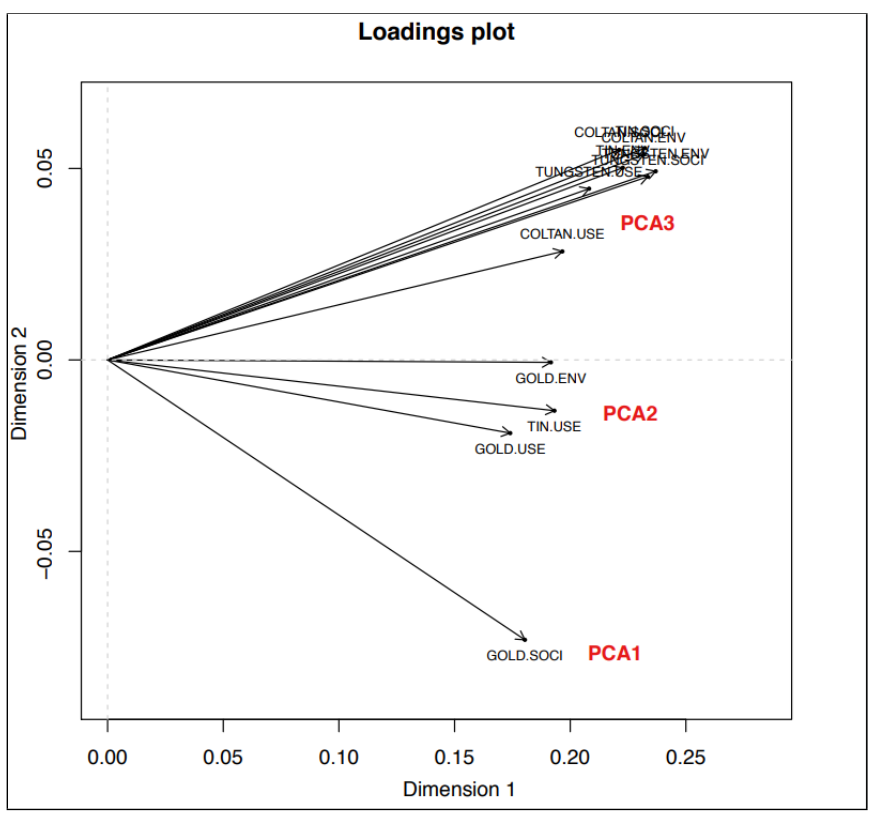

Figure 7: Non-linear Principal Component Analysis Results. 3 different clusters can be identified: (1) PCA1: Participants who knew about the societal impacts of gold (2) PCA2: Participants who knew about the use of gold, the environmental impacts of gold and the use of tin (3) PCA3: Participants who knew about all remaining factors 


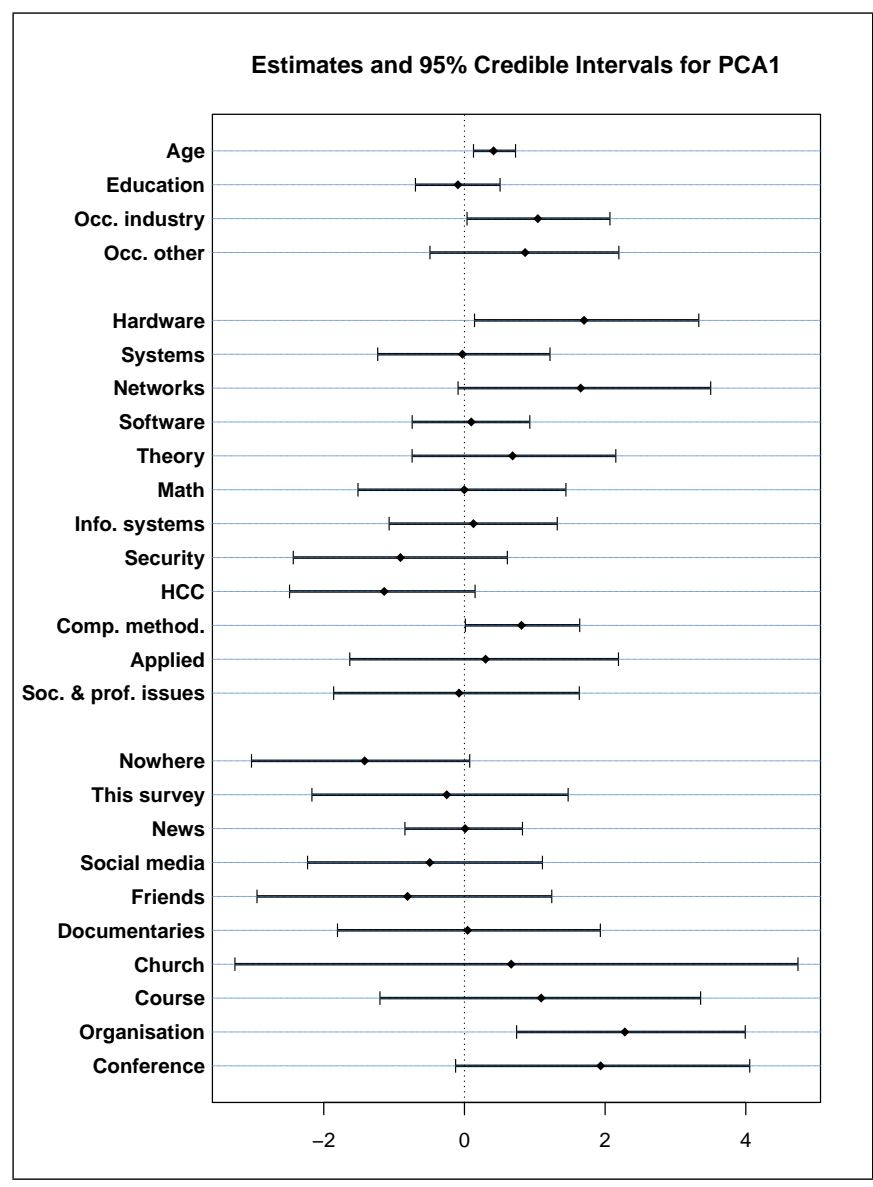

Figure 8: Coefficient estimates and 95\% credible intervals for regression predicting PCA1. The results suggest increased knowledge of this cluster among participants who are older, work in industry, specialize in hardware or computing methodologies, or have learned about conflict minerals through organizations.

Results for PCA1 (Figure 8) show that computer scientists specialized in hardware and computing methodologies know the most about the societal impacts of gold whereas human-centred computing specialists know the least. Furthermore, learning about those via organisations is the most effective. Age and belonging to industry also seem to positively influence this knowledge.

For the gold and tin use and the environmental impacts of gold (PCA2, Figure 9), specialists in hardware were the most knowledgeable and, conferences, organisations and the news are the most effective places to learn about these topics. Here again age seems to play an important role and, belonging neither to academia nor to industry had a positive impact.

Lastly, for the third cluster (PCA3, Figure 10), the variables that seemed to play an important role were if people learned about conflict minerals via organisations or through courses or the news and, if specializing in hardware, networks or computing methodologies. Age again seem to positively impact this knowledge.

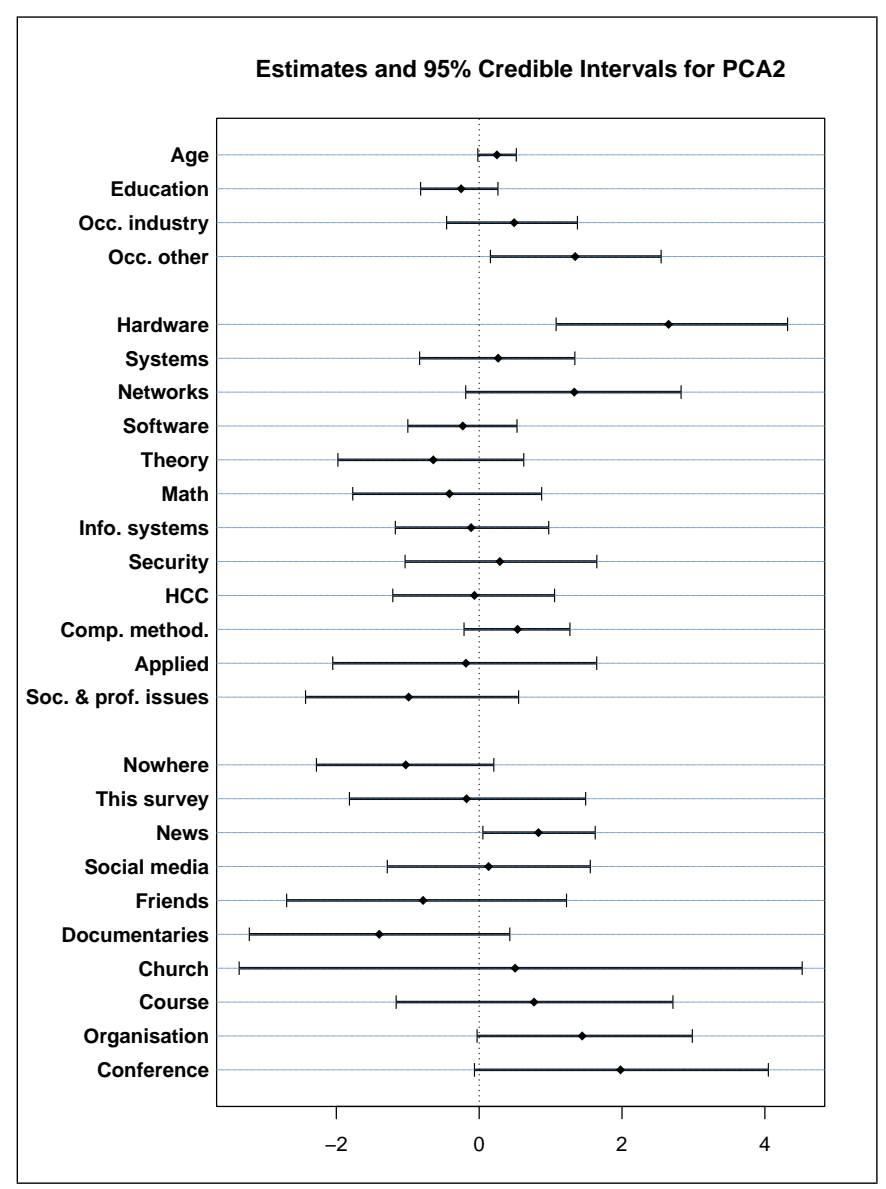

Figure 9: Coefficient estimates and 95\% credible intervals for regression predicting PCA2. The results suggest increased knowledge of this cluster among participants who are older, work in neither academia nor industry, specialize in hardware, or have learned about conflict minerals through conferences, organizations or the news.

\subsection{Pseudo-Qualitative analysis}

Overall, our open-ended responses were quite brief and to the point.

"War, poverty, exploitation"

"Energy usage, social alienation, micro targeting, access" Make devices that last longer! :)

There was not much in the way of qualitative richness; as a result our analysis focused on the categories of the the content that was provided.

4.3.1 Knowledge on conflict minerals. The first open-ended question in the survey was: "When you hear 'conflict minerals', what are the first 2-3 things that come to mind for you?". $30 \%$ of the participants in the survey decided to leave this question blank or mentioned that they had no idea and/or had never heard the term before. The rest of the responses can be grouped by their mentions of elements in 
10 different categories: violence, poverty and exploitation, electronics, raw materials, geographic locations, capitalism, environment, mining, health problems and ethics.

In the category of violence, which had 27 mentions amongst respondents, participants brought up ideas of war, terrorism, smuggling, gangs and corruption. The most mentioned topic in this category was war, with 23 mentions.

For the poverty and exploitation category, most respondents talked about exploitation (21 mentions); other topics brought up were child labor ( 9 mentions), social conflict ( 2 mentions) and poverty (6 mentions).

18 respondents talked about electronics and how conflict minerals were used in their components (14 of them generally, and 4 specifically talking about batteries).

The category with the most mentions was raw materials, with 22 mentions of rare minerals and 29 mentions of diamonds. Only a few participants mentioned some of the 3TG minerals (6 mentions for gold, 2 for tungsten and tin and 8 for tantalum) and other participants mentioned other minerals, metals and chemicals such as cobalt ( 9 mentions) or lithium (5 mentions).

In terms of geographical locations, Africa was mentioned 13 times, while other locations such as Southeast Asia and China were mentioned only mentioned once and twice respectively.

There were a couple mentions in the category of capitalism: 2 of consumerism, 2 of corporatism, 2 of competition, 1 of colonialism and 1 of supply chains.

Some respondents brought up themes in the category of the environment too, most of them referring to the environmental damage conflict minerals may cause (11 mentions). Other mentions in this category included topics of disposal and waste (5 mentions) and recycling (4 mentions).

Finally, there were 17 mentions of mining, 4 mentions of problems related to health and 7 mentions of ethics.

4.3.2 Other impacts of electronics. The second open-ended question in the survey was: "Besides conflict minerals, can you list 2-5 other ways that electronics impact the environment and/or society?". Most participants responded this time, only 7 left the question blank.

For the environmental impacts, $65 \%$ of the responses mentioned e-waste as well as the poor recycling of electronics (7 mentions). $30 \%$ of the responses mentioned the link between electronics and climate change (carbon footprint, global warming...) and $22 \%$ mentioned issues related to the energy consumption of devices and need of electricity (which in many countries is supplied by non-sustainable sources).

For the social impacts, respondents listed both positive and negative effects of electronics and their use. On the positive side, there were mentions of how electronics improve communications (14 mentions), allow the sharing of knowledge (7 mentions), innovate (5 mentions) and make processes more efficient (3 mentions). There were also mentions of the importance of electronics in the society we live in and how electronics have contributed to social change (7 mentions): change in work due to automation, access to education, etc.

On the negative side, most mentions concerned the problem of exploitation and poor labor practices in electronics manufacturing

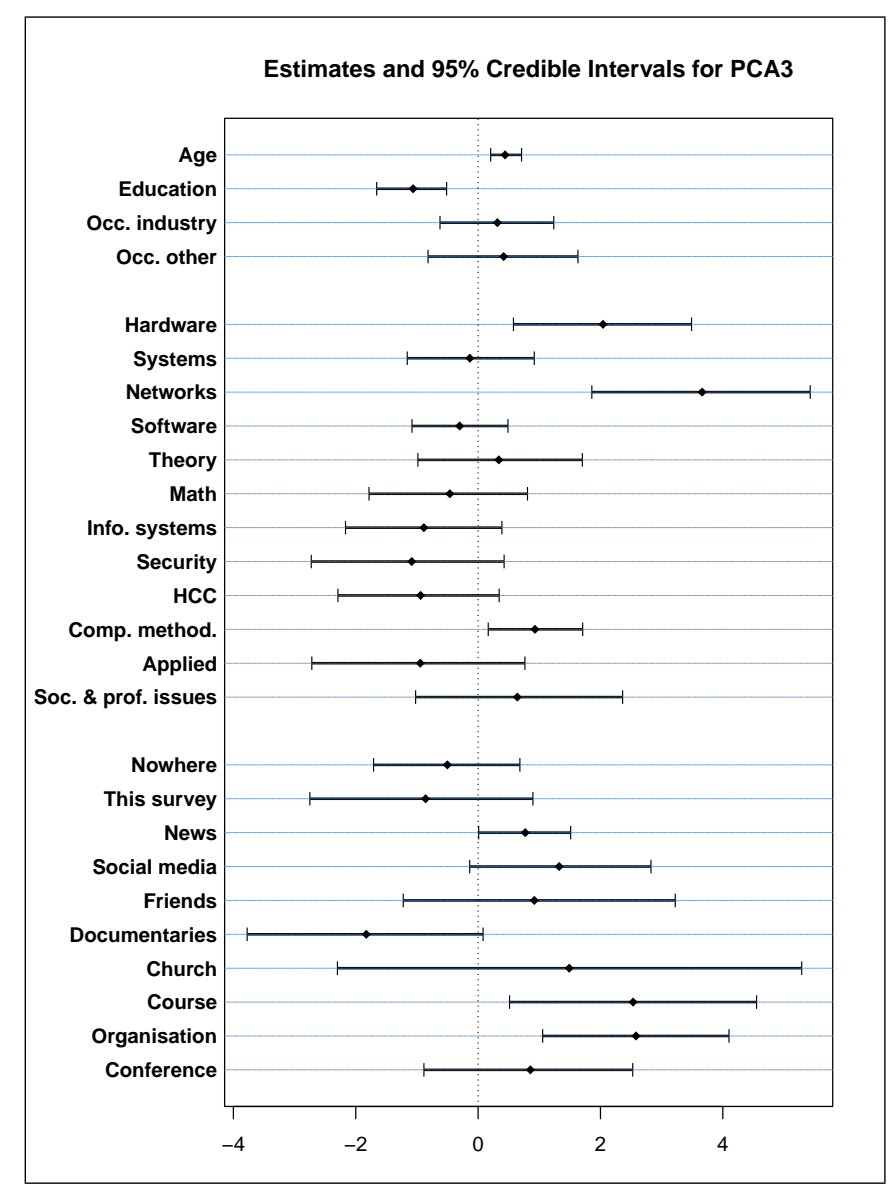

Figure 10: Coefficient estimates and 95\% credible intervals for regression predicting PCA3. The results suggest increased knowledge of this cluster among participants who are older, specialize in hardware, networks or computing methodologies, and have learned about conflict minerals through organizations or courses.

(13 mentions), the problem of alienation to technology (12 mentions) and the unequal access to it (i.e. the digital divide, "People at different income levels have different access to computational devices. This means that poorer students might have less fluency with typing/navigating a computer compared to more wealthy students" )(13 mentions). Other topics brought up included privacy and surveillance (6 and 5 mentions), discrimination and bias in algorithms (5 mentions) and disinformation (4 mentions).

4.3.3 Solutions. When asked "What are some solutions you can think of to address the social or environmental impacts of electronics?", 17 participants left the question blank and the rest gave a wide range of answers.

One of the most mentioned topics was recycling and reuse, with 43 and 20 mentions respectively. The reduction of consumption and repair was only mentioned 4 and 6 times respectively. ("I try to hold off on upgrades as much as possible, but sometimes good opportunities or sales overwhelm my will"). 
Then, many participants alluded to the requirement of standards (5 mentions) or to holding manufacturers responsible for the technology they create (15 mentions). There were also 24 responses that touched on the need for legislation and international agreements to regulate technology manufacturing.

10 respondents talked about the need to include this topic in education ("Have all computer scientists know about this problems") and 15 talked about activism: 'raising awareness' was mentioned 9 times ("It's not a solution, but get people to talk about these problems more so CS professionals are more aware. I try to talk about CS Ethics in every CS class I teach to help with this.") and boycotts were mentioned 5 .

Finally, some respondents touched upon topics of research and the creation of new technologies that last longer ( 8 mentions) and use more sustainable materials or energy (6 mentions).

Only one participant mentioned that they were not concerned with the topic and that it "wasn't a real issue" ("None? On the balance they are so vastly better than not having them that I don't think this is a real issue.") while some were more critical about tech professions as a whole ("First of all: be honest. Everything has a price. Digitization is not a solution for everything but also creates problems. There is no 'green IT'. Analyze the specific problems and then find appropriate solutions.", "I'm not sure what this question means. Being part of the industry means being part of the problem.")

4.3.4 Actions. For the last question, "Have you ever taken action or contributed to causes related to the social or environmental impacts of electronics?", $54 \%$ of respondents left their answer blank and/or said they had nothing to mention.

There were 27 mentions of recycling, 3 mentions of second-hand purchasing and 5 mentions of repair. Other topics mentioned were holding off on upgrades (11 mentions) and thoughtful or informed purchasing (6 mentions).

Other participants mentioned they had contributed to this cause through work. Either by educating students (5 mentions), writing and publishing about some of these topics (2 mentions), talking at venues ( 2 mentions) or other work-related projects (5 mentions).

Finally, 3 participants mentioned their activism and 12 mentioned electronics donations and/or financial support of organisations and institutions such as the Electronic Frontier Foundation (EFF), the Free Software Foundation (FSF), the Texas Campaign for the Environment or the Union of Concerned Scientists amongst others.

\section{DISCUSSION}

The results indicate that gold is the most known conflict mineral. This is understandable as gold has historically been a store for value and has been used for a multitude of things outside electronics (as currency, in jewelry and ornaments, etc) [15]. Additionally, when hearing the term 'conflict minerals' many participants made the connection to blood diamonds, which is similar to conflict minerals in that diamonds are mined in war zones and sold to finance such conflicts (especially in African countries such as Angola, Ivory Coast, Sierra Leone, Liberia, Guinea and Guinea Bissau) [48]. This is explained by the fact that conflict diamonds became a popular topic in 2006, with the release of the movie Blood Diamonds, a political war thriller set during the Sierra Leone Civil War in 19912002 that starred Leonardo DiCaprio and drew significant media attention to the issue.

Interestingly, participants brought up other geographical locations outside the DRC when thinking about the term 'conflict minerals'. Indeed, the problems with mining are in no way limited to the current definition of conflict minerals. As suggested by participants' responses, human rights abuses and environmental destruction associated with mining have been well-documented in many countries $[2,3,8,20]$. Our paper uses the accepted legal definition of conflict minerals which was developed with the implementation of the Dodd-Frank Act, which was the first major legislation against conflict minerals. Currently, the term only designates tin, tungsten, tantalum and gold mined in conflict zones of the DRC, however other standards and programs provide a broader definition of the term. For example, the OECD considers tin, tungsten, tantalum and gold sourced from "conflict-affected and high-risk" areas throughout the globe. Furthermore, the scope of the "conflict minerals' list is not fixed and could be expanded to include other minerals mentioned by participants such as cobalt [47].

Results also indicated that older participants know more about the use of conflict minerals and their impacts than younger ones. This result can also be explained by the fact that in 2010, when the Dodd-Frank Act was enacted in the United States, conflict minerals became a hot topic that trended in the news. Consequently, participants that were at adult age at that time were likely exposed to this information and became more informed about these issues. This also explains why for PCA2, news appeared to be an effective place to learn about conflict minerals. However, none of the participants mentioned this legislation when asked about conflict minerals. This was surprising, as in the solutions open-ended question, one of the topics with the most mentions was precisely the need for legislation and/or international agreements and standards to regulate the market of minerals and have more transparent supply chains. Unfortunately, the current legislation has been proven to be ineffective not only because companies are usually unable to verify their products' conflict-free status [24] but also because it is negatively affecting the livelihoods of Congolese mining communities as well as strengthening the minerals' black market [40].

As seen in figures 8-10, there was noticeable variation between different specialties within computing in terms of conflict mineralrelated knowledge. Unsurprisingly, listing hardware as a specialty within computing was associated with greater knowledge of conflict minerals, as was networks. But we were surprised and disappointed to see that listing human-centred computing as a specialty was a negative factor in PCA1 at the $90 \%$ credible interval level, and that social and professional issues in computing was no better than average.

In the 'solutions' open-ended question, many people mentioned the importance of recycling and reuse, but there were very little mentions of the other two Rs higher up in the waste management hierarchy: reduce and repair. The waste hierarchy is a tool that aims to extract the maximum practical benefits of products while generating the minimum amount of waste and being the least harmful to the environment [18]. Its recommended actions from most favourable to least favourable are: reduce, reuse, repair and recycle. E-waste is one of the fastest growing waste streams globally, with 
a growth rate of $21 \%$ in the last five years; The Global E-waste Monitor 2020 report found that 53.6 million tonnes of e-waste were dumped in 2019 [14]. Furthermore, recycling of conflict minerals is still not widespread and the recycling rates for each mineral do not surpass 34\% (33\% for tin, 30\% for tungsten, $15-20 \%$ for tantalum and $34 \%$ for gold) [4]. It is important then to also consider other factors in the waste management hierarchy, for example the right to repair The right to repair movement aims to promote government legislation that will allow consumers of electronics to repair and modify their own devices. It is inscribed within the transition to a Circular Economy (CE), an economy which proposes a more efficient use of resources by considering the way products are designed and used to promote longer-lasting devices. In the United States and within the European Union, debates around the issue have been ongoing but are still facing barriers [43].

This study supports the idea that members of the Computer Science community are very unaware of the social and environmental impacts of their technologies, especially when it comes to the use of conflict minerals in electronics. While people in the LIMITS community have made some inroads in having climate change and sustainability issues brought into CS curricula (e.g. [9, 28-30, 51]) and promoting connections between CS students and non-computer scientists (e.g. [5, 34]), our study highlights how we have further to go in terms of including issues of conflict minerals and reducing e-Waste.

Indeed, results show that the only factors that seem to influence conflict mineral knowledge are education and whether or not individuals have learned about the topic via organisations or courses. This suggests a need to include such topics in curricula and move beyond the narrow focus on technical material that many universities have. Learning about contextual concepts and the social and global impact of technology is critical for students as it enables them to frame their careers as sociotechnical rather than purely technical [9, 12, 17, 23, 28-30]. Moreover, Lord et al. reported the positive experience of instructors and the enthusiasm of students when teaching a module about conflict minerals in a second year Electrical Circuits course at the University of San Diego [27]. Even though this can be difficult for some instructors whose expertise is mainly technical, curricular shift is needed to prepare students for their future professional practice and to make them aware of how their work relates to peace, sustainability, and social justice. Moreover, with a confidence interval barely crossing 0 for both PCA1 and PCA2, we could argue that conferences are also a great place to learn about these topics, suggesting a potential avenue for action. One could imagine that, if social and environmental issues of technology are further discussed in conferences, computer scientists with a purely technical training will become more aware and this will also facilitate the curricular shift discussed above.

Unfortunately, learning and teaching about sustainability does come with an emotional and psychological cost, but change does not come by taking the easy path [25]. We as researchers must learn to work with and through our own barriers, bringing forward all friction and tension "as they are the precursors of change, and a necessary precondition for understanding where there is more work to do, where our efforts can have reverberations, and hence where we should direct our energies" [11].

\subsection{Limitations}

The statistical generalizability of the results is limited by the sampling of the study: the sample of participants was highly-educated, with most of them holding a Doctorate and mainly in academia, which is not necessarily representative of the entire computer science community. Indeed, in Canada, only $55 \%$ of workers in the ICT sector hold a University degree [16]. This was certainly also influenced by the recruiting method, as the survey was mainly sent out to professionals in research institutes such as Mila and the ACM SIGs.

Moreover, the recruitment method used may have induced a sampling bias favoring respondents who were more aware of conflict minerals and supply chain processes. It is plausible that computer scientists who have some existing knowledge of the role of conflict minerals in their industry would be more likely to respond to the recruitment announcement. In this case, our results would indicate overall higher overall awareness of the role of conflict minerals in the ICT sector than there actually is.

Finally, data collected in this survey was self-reported and cannot be independently verified. Self-reported data can contain several potential sources of bias such as selective memory, for example.

\subsection{Future work}

This study focused on the awareness of computer scientists about conflict minerals, but other topics in the environmental and/or social impacts of electronics could be studied similarly (e.g. the digital divide, the global trade in highly toxic e-waste, recycling of electronic components...). As suggested by our findings, one could also study this topic using a broader definition of conflict minerals.

Further research can also be conducted to record and analyze people's reactions and opinions when faced with the topic of conflict minerals for the first time or to survey general public opinions on the effectiveness of current legislation about conflict minerals. This study could be replicated surveying the general public and contrasting their level of awareness and knowledge about these issues with that of ICT professionals.

\section{CONCLUSION}

The purpose of this research project was to examine the awareness of computing professionals about social and environmental impacts related to the creation, use and distribution of electronics, focusing on the use of conflict minerals. Through an online survey, members of the Computer Science community in academia and industry were invited to answer a variety of questions that sought to explore their knowledge on conflict minerals and other social and environmental impacts of electronics. A total of 135 participant responses were recorded and analyzed. A quantitative analysis was performed to investigate correlations between participant demographic information and their level of familiarity with conflict minerals, followed by a pseudo-qualitative analysis which identified common themes in participants' responses about their knowledge of other socioenvironmental issues related to the electronics industry as well as possible solutions and actions that can be taken to remedy those issues.

Findings showed that a greater part of computing professionals are not familiar with these issues, which supports the need of 
including topics on technology's social and global impacts in curricula. Our results suggest that learning about conflict minerals in professional settings (e.g. courses) can be particularly useful for raising awareness about the environmental and social impacts of electronics. Recycling was suggested by participants as a possible solution many times, but reducing and reusing were not brought up as often, indicating a greater need to educate computer scientists about sustainability.

\section{ACKNOWLEDGMENTS}

Thank you to all computing professionals that participated in our survey.

Thank you to Oliver Bates, Christoph Becker, Loreina Chew, Hana Darling-Wolf, Elina Eriksson, Anna Ma, Eric Mayhew, Samuel Mann, Emma McKay, and Jess Tran for feedback on drafts.

Thank you to colorbrewer2.org for providing free colourblindfriendly palettes for graphing.

\section{REFERENCES}

[1] Abiodun Alao. 2007. Natural resources and conflict in Africa: the tragedy of endowment. Vol. 29. University Rochester Press.

[2] Moisés Arce and Rebecca E Miller. 2016. Mineral wealth and protest in SubSaharan Africa. African Studies Review 59, 3 (2016), 83-105.

[3] Clive Aspinall and P Eng. 2001. Small-scale mining in Indonesia. International Institute for Environment and Development and the World Business Council for Sustainable Development, England 79 (2001)

[4] Bali Barume, Uwe Naeher, Désirée Ruppen, and Philip Schütte. 2016. Conflict minerals (3TG): Mining production, applications and recycling. Current Opinion in Green and Sustainable Chemistry 1 (2016), 8-12.

[5] Oliver Bates, Carolynne Lord, Hayley Alter, and Ben Kirman. 2020. Let's Start Talking the Walk: Capturing and Reflecting on Our Limits When Working with Gig Economy Workers. In Proceedings of the 7th International Conference on ICT for Sustainability (Bristol, United Kingdom) (ICT4S2020). Association for Computing Machinery, New York, NY, USA, 227-235. https://doi.org/10.1145/ 3401335.3401364

[6] Raimund Bleischwitz, Monika Dittrich, and Chiara Pierdicca. 2012. Coltan from Central Africa, international trade and implications for any certification. $R e-$ sources Policy 37, 1 (2012), 19-29.

[7] Paul-Christian Bürkner and Emmanuel Charpentier. 2018. Modeling Monotonic Effects of Ordinal Predictors in Bayesian Regression Models. (2018)

[8] Cathal Doyle, Clive Wicks, and Frank Nally. 2007. Mining in the Philippines: Concerns and conflicts. Fact Finding Mission to the Philippines report. Columban Fathers. West Midlands, UK (2007).

[9] Steve Easterbrook. 2014. From Computational Thinking to Systems Thinking: A conceptual toolkit for sustainability computing. In ICT for Sustainability 2014 (ICT4S-14). Atlantis Press.

[10] Marc J Epstein and Kristi Yuthas. 2011. Conflict minerals: Managing an emerging supply-chain problem. Environmental Quality Management 21, 2 (2011), 13-25.

[11] Elina Eriksson and Daniel Pargman. 2017. On the inherent contradictions of teaching sustainability at a technical university. (2017).

[12] Casey Fiesler, Natalie Garrett, and Nathan Beard. 2020. What Do We Teach When We Teach Tech Ethics? A Syllabi Analysis. In Symposium on Computer Science Education (SIGCSE'20).

[13] Colin Fitzpatrick, Elsa Olivetti, T Reed Miller, Richard Roth, and Randolph Kir chain. 2015. Conflict minerals in the compute sector: estimating extent of tin tantalum, tungsten, and gold use in ICT products. Environmental science \& technology 49, 2 (2015), 974-981.

[14] Vanessa Forti, Cornelis P Baldé, Ruediger Kuehr, and Garam Bel. 2020. The global $e$-waste monitor 2020: Quantities, flows and the circular economy potential. United Nations University (UNU)/United Nations Institute for Training and Research (UNITAR), International Telecommunication Union (ITU), and International Solid Waste Association (ISWA). 120 pages.

[15] GHGm. 2008. Social and Environmental Responsibility in Metals Supply to the Electronic Industry.

[16] Government of Canada. 2019. Canadian ICT Sector Profile 2019. https://www.ic gc.ca/eic/site/ict-tic.nsf/eng/h_it07229.html.

[17] Horațiu Halmaghi. 2019. Learning computer science was hard. Unlearning computer science is harder. Master's thesis. McGill University.

[18] Wenke Hansen, Maria Christopher, and Maic Verbuecheln. 2002. EU waste policy and challenges for regional and local authorities. Ecological Institute for
International and European Environmental Policy: Berlin, Germany (2002), 19.

[19] Karen Hayes and Rachel Perks. 2012. Women in the artisanal and small-scale mining sector of the Democratic Republic of the Congo. High-value natural resources and peacebuilding (2012), 529-544

[20] Shin Imai, Leah Gardner, and Sarah Weinberger. 2017. The'Canada Brand': Violence and Canadian Mining Companies in Latin America. Osgoode Legal Studies Research Paper 17 (2017), 132.

[21] N Jordan Jameson, Xin Song, and Michael Pecht. 2016. Conflict minerals in electronic systems: an overview and critique of legal initiatives. Science and engineering ethics 22, 5 (2016), 1375-1389.

[22] Somya Joshi and Teresa Cerratto Pargman. 2015. In Search of Fairness: Critica Design Alternatives for Sustainability. In Proceedings of The Fifth Decennial Aarhus Conference on Critical Alternatives (CA '15). Aarhus University Press, Aarhus N, 37-40. https://doi.org/10.7146/aahcc.v1i1.21301

[23] Michelle Kaczmarek, Saguna Shankar, Rodrigo dos Santos, Eric M. Meyers, and Lisa P. Nathan. 2020. Pushing LIMITS: Envisioning beyond the Artifact. In Proceedings of the 7th International Conference on ICT for Sustainability (Bristol, United Kingdom) (ICT4S2020). Association for Computing Machinery, New York, NY, USA, 255-266. https://doi.org/10.1145/3401335.3401367

[24] Yong H Kim and Gerald F Davis. 2016. Challenges for global supply chain sustainability: Evidence from conflict minerals reports. Academy of Management fournal 59, 6 (2016), 1896-1916.

[25] Bran Knowles and Elina Eriksson. 2015. Deviant and guilt-ridden: Computing within psychological limits. First Monday (2015).

[26] Thung-hong Lin, Yi-ling Lin, and Wei-lin Tseng. 2016. Manufacturing suicide: The politics of a world factory. Chinese Sociological Review 48, 1 (2016), 1-32.

[27] S. M. Lord, B. Przestrzelski, and E. Reddy. 2018. Teaching Social Responsibility: Conflict Minerals Module for a Circuits Class. In 2018 World Engineering Education Forum - Global Engineering Deans Council (WEEF-GEDC). 1-6. https://doi.org/ 10.1109/WEEF-GEDC.2018.8629755

[28] Samuel Mann, Karyn Costello, D Lopez, and N Smith. 2014. An Ethical Basis for Sustainability in the World Views of First Year Students. In 2nd International Conference on ICT for Sustainability (ICT4S 2014). Atlantis Press, 120-131.

[29] Samuel Mann, Mike Lopez, Dobrila Lopez, and Nell Smith. 2015. Educating for ICT4S: Unpacking sustainability and ethics of ICT student intakes. In 29th International Conference on Informatics for Environmental Protection and the 3rd International Conference ICT for Sustainability (EnviroInfo \& ICT4S 2015). Atlantis Press, 229-241.

[30] Samuel Mann, Lesley Smith, and Logan Muller. 2008. Computing Education for Sustainability. SIGCSE Bull. 40, 4 (Nov. 2008), 183-193. https://doi.org/10.1145/ 1473195.1473241

[31] Jeffrey W Mantz. 2008. Improvisational economies: Coltan production in the eastern Congo. Social Anthropology 16, 1 (2008), 34-50.

[32] Emma McKay. 2021. Dis-origined Materials: The Role and Invisibilization of Extraction in Technoscience. https://doi.org/10.31235/osf.io/8hxj7

[33] Bonnie Nardi, Bill Tomlinson, Donald J. Patterson, Jay Chen, Daniel Pargman, Barath Raghavan, and Birgit Penzenstadler. 2018. Computing within Limits. Commun. ACM 61, 10 (Sept. 2018), 86-93. https://doi.org/10.1145/3183582

[34] Vineet Pandey, Krzysztof Z Gajos, and Anoopum S Gupta. 2020. From novices to co-pilots: Fixing the limits on scientific knowledge production by accessing or building expertise. In Proceedings of the 7th International Conference on ICT for Sustainability. 294-304.

[35] Daniel Pargman and Björn Wallsten. 2017. Resource scarcity and socially just internet access over time and space. In Proceedings of the 2017 Workshop on Computing Within Limits. 29-36.

[36] Devin N Perkins, Marie-Noel Brune Drisse, Tapiwa Nxele, and Peter D Sly. 2014. E-waste: a global hazard. Annals of global health 80, 4 (2014), 286-295.

[37] Ross Perlin. 2013. Chinese Workers Foxconned. Dissent 60, 2 (2013), 46-52.

[38] F. Piasecki Poulsen. 2012. Children of the Congo who risk their lives to supply our mobile phones. https:/www.theguardian.com/sustainable-business/blog/congochild-labour-mobile-minerals

[39] John Prendergast and Sasha Lezhnev. 2009. From mine to mobile phone. The Conflict Minerals Supply Chain. Washington DC: Enough Project (2009).

[40] Ben Radley and Christoph Vogel. 2015. Fighting windmills in Eastern Congo? The ambiguous impact of the 'conflict minerals' movement. The Extractive industries and society 2, 3 (2015), 406-410.

[41] Shannon Raj. 2010. Blood Electronics: Congo's Conflict Minerals and the Legislation That Could Cleanse the Trade. Southern California Law Review 84, 4 (2010), 981-1034.

[42] Fleur Scheele, Esther de Haan, and Vincent Kiezebrink. 2016. Cobalt Blues: Environmental pollution and human rights violations in Katanga's copper and cobalt mines',. Amsterdam. Online available at https://www. somo. $\mathrm{nl} / \mathrm{nl} / \mathrm{wp}$ content/uploads/sites/2/2016/04/Cobalt-blues. pdf, last accessed 27 (2016), 2017.

[43] Sahra Svensson, Jessika Luth Richter, Eléonore Maitre-Ekern, Taina Pihlajarinne, Aline Maigret, and Carl Dalhammar. 2018. The emerging 'Right to repair'legislation in the EU and the US. Proceedings from Going Green-Care Innovation, Vienna (2018) 
[44] Sy Taffel. 2012. Escaping attention: Digital media hardware, materiality and ecological cost. Culture Machine 13 (2012).

[45] Sy Taffel. 2015. Towards an Ethical Electronics? Ecologies of Congolese Conflict Minerals. Westminster Papers in Communication and Culture 10, 1 (2015).

[46] Team Human. 2017. Bas Van Abel "Fingerprints On The Touchscreen" https://www.teamhuman.fm/episodes/ep-30-bas-van-abel-fingerprints-onthe-touchscreen/.

[47] Nicolas Tsurukawa, Siddharth Prakash, and Andreas Manhart. 2011. Social impacts of artisanal cobalt mining in Katanga, Democratic Republic of Congo. Óko-Institut eV, Freiburg (2011).

[48] United Nations Department of Public Information. 2001. Conflict Diamonds. https://web.archive.org/web/20121023004513/http://www.un.org/peace/ africa/Diamond.html

[49] Daan Van Brusselen, Tony Kayembe-Kitenge, Sébastien Mbuyi-Musanzayi, Toni Lubala Kasole, Leon Kabamba Ngombe, Paul Musa Obadia, Daniel Kyanika wa Mukoma, Koen Van Herck, Dirk Avonts, Koen Devriendt, et al. 2020. Metal mining and birth defects: a case-control study in Lubumbashi, Democratic Republic of the Congo. The Lancet Planetary Health 4, 4 (2020), e158-e167.

[50] Christoph Vogel. 2017. Armed Group Maps. https://suluhu.org/congo/mapping/

[51] Huaxin Wei, Jeffrey C. F. Ho, Kenny K. N. Chow, Shunying An Blevis, and El Blevis. 2019. Should Do, Can Do, Can Know: Sustainability and Other Reflections on One Hundred and One Interaction Design Projects. In Proceedings of the Fifth Workshop on Computing within Limits (Lappeenranta, Finland) (LIMITS '19). Association for Computing Machinery, New York, NY, USA, Article 6, 18 pages. https://doi.org/10.1145/3338103.3338109

[52] Karen E. Woody. 2012. Conflict Minerals Legislation: The SEC's New Role as Diplomatic and Humanitarian Watchdog. Fordham Law Review 81, 3 (2012) 1315-1352.

\section{A APPENDIX: SURVEY}

(See next page) 


\section{What do computer scientists know about conflict minerals?}

Purpose of study: The purpose of this research project is to examine the awareness of computing professionals about social and environmental impacts related to the creation, use, and distribution of electronics, focusing on the use of conflict minerals. This is a research project conducted by Ines Moreno under the supervision of Dr. Elizabeth Patitsas as part of a credited course at McGill University.

Study procedures: You are invited to participate in this research project because you belong to the Computer Science community in either academia or industry. You will be asked to answer an online survey which will take you around 15 minutes to complete. The questions look to explore your knowledge on conflict minerals and other social and environmental impacts of electronics.

Participation: Your participation in this study is completely voluntary. You may, at any time, refuse to participate in parts of the study, decline to answer a question, or withdraw from the study. If you choose to withdraw from the study, please contact Ines

(ines.moreno@mail.mcgill.ca) specifying the date and time you submitted the survey; your information will then be destroyed.

There will be no monetary remuneration for participating in this study.

Confidentiality: We will not be asking your name or other personally-identifying information, and so your responses will be anonymous. We are not logging IP addresses. The results of this study will be used for scholarly purposes only.

Potential risks: You may feel uncomfortable while completing the survey, in which case we reiterate that you are not required to answer all questions and may terminate at any time. Your responses will only be recorded if you hit "submit" at the end of the survey. Because this survey is hosted through Google forms please note that the data is presumed to be stored in the United States and would be subject to the Patriot Act.

If you would prefer a version of the survey hosted in Canada, you may fill in the survey HERE: https://forms.office.com/Pages/ResponsePage.aspx?id=cZYxzedSaEqvqfz4-

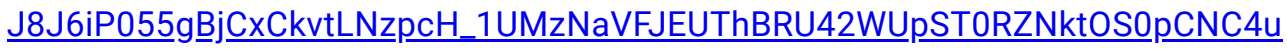

Potential benefits: You may find this survey to be a useful opportunity to reflect and learn about aspects that are not often discussed in the computer science community.

Questions: If you have any questions about the research, please contact Ines Moreno (ines.moreno@mail.mcgill.ca). If you have any ethical concerns or complaints about your participation in this study, contact the supervisor of the study, Dr. Elizabeth Patitsas (elizabeth.patitsas@mcgill.ca)

Clicking on the "agree" button below indicates that:

- you have read the above information

- you voluntarily agree to participate

- you are 18 or over 
- you are a professional computer scientist or other computing professional (e.g. software engineer)

If you do not wish to participate in the research study, please decline participation by clicking on the "disagree" button.

* Required

1. Do you consent to participate in the survey? *

Mark only one oval.
$\bigcirc$ Agree
Disagree

\section{About you}

2. What is your age group?

Mark only one oval.

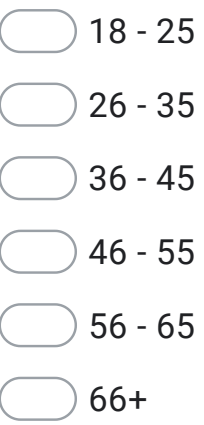

3. Highest level of education completed

Mark only one oval.

High school / secondary school

CEGEP, community college

$\bigcirc$ Certification programme (e.g. coding bootcamp)

Bachelor's degree

$\longrightarrow$ Master's degree

Doctorate 
4. What is your current (or most recent) occupation? *

5. Do you have a specialty within computer science?

Check all that apply.

$\square$ Hardware

$\square$ Computer systems organization

$\square$ Networks and web/mobile computing

$\square$ Software and its engineering

$\square$ Theory of computation

Mathematics of computing

$\square$ Information systems

$\square$ Security and privacy

$\square$ Human-centred computing

Artifical intelligence, machine learning, graphics, and other computing methodologies

Applied computing (e.g. computational biology, computational social science)

$\square$ Social and professional issues in computing

Other:

Familiarity with conflict minerals

6. When you hear "conflict minerals", what are the first 2-3 things that come to mind for you? 
7. How familiar are you with how <given mineral> is used in electronics? *

Mark only one oval per row.

\begin{tabular}{l}
$\begin{array}{c}\text { Expert on } \\
\text { this }\end{array}$ \\
\hline Gold \\
$\begin{array}{l}\text { Tungsten } \\
\text { (Wolframite) }\end{array}$ \\
$\begin{array}{l}\text { Tantalum } \\
\text { (Coltan) }\end{array}$
\end{tabular}

8. How familiar are you with the environmental effect of <given mineral>? * Mark only one oval per row.

Expert on
this Familiar $\begin{gathered}\text { Somewhat } \\ \text { familiar } \\ \text { Tungsten } \\ \text { Tholframite) }\end{gathered}$


9. How familiar are you with the social effect of <given mineral>? *

Mark only one oval per row.

\begin{tabular}{l}
$\begin{array}{c}\text { Expert on } \\
\text { this }\end{array}$ \\
\hline $\begin{array}{l}\text { Tungsten } \\
\text { Wolframite) }\end{array}$
\end{tabular}

10. Where have you learned about conflict minerals from?

Skip to question 11

Social \& environmental impacts of electronics

11. Besides conflict minerals, can you list 2-5 other ways that electronics impact the environment and/or society? 
12. What are some solutions you can think of to address the social or environmental impacts of electronics (such as the ones you just listed, conflict minerals, etc)?

13. Have you ever taken action or contributed to causes related to the social or environmental impacts of electronics? List actions you have done.

Final questions

14. Do you have any other thoughts or comments you would like to share?

15. If you agree to be contacted to follow-up on your answers, please enter your email. Your email will only be used for follow-up purposes. 


\section{B APPENDIX: RECRUITING MATERIALS}

\section{B.1 Email/Linkedin}

5-15 mins survey about impacts of electronics

Hi all,

My name is Ines Moreno and I am a Computer Science student at McGill University doing a research project under the supervision of Dr. Elizabeth Patitsas. The purpose of my study is to find out how much computer scientists know (or don't know) about the social and environmental impacts of electronics, especially focusing on the use of conflict minerals.

I have prepared an online survey that takes around 5-15 minutes to complete and that asks how much you know (or don't know) about these impacts: https://tinyurl.com/CSConflictMinerals

I am looking for participants who are computing professionals in academia and industry and would greatly appreciate it if you could share this survey with colleagues. No prior knowledge of conflict minerals is necessary for the survey - we want to find out how many people know or don't know about them! :)

To allow for anonymity, at no point in the survey will we ask you for your name, and we will not be logging your IP address.

If you'd like more information on the study, feel free to contact me with your questions.

Thank you very much for your time.

Best,

\section{B.2 Twitter}

(2) Dr. Elizabeth Patitsas 9 여 \#BlackLivesMatter

@patitsel

Are you a computer scientist or computing professional? My student Ines Moreno is surveying how much CS folks know about impacts of electronics and would like your help! All levels of knowledge about soc/env impacts are welcome! 5-15 minute survey: tinyurl.com/CSConflictMine...

11:48 p. m. $\cdot 29$ jul. 2020 - Twitter Web App 